\title{
Novel ascorbic acid sensor prepared from gold/aniline-pentamer-based electroactive polyamide composites
}

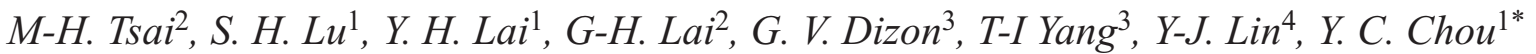 \\ ${ }^{1}$ Department of Applied Cosmetology, Hung Kuang University, 43302 Sha Lu, Taichung, Taiwan, R.O.C \\ ${ }^{2} \mathrm{Ph}$. D. Program, Graduate Institute of Precision Manufacturing, National Chin-Yi University of Technology, 41170 \\ Taichung, Taiwan, R.O.C. \\ ${ }^{3}$ Department of Chemical Engineering, Chung Yuan Christian University, 32023 Chung Li, Taiwan, R.O.C. \\ ${ }^{4}$ Department of Chemical Engineering, National Tsing Hua University, Hsinchu 30013, Taiwan, R.O.C.
}

Received 16 June 2017; accepted in revised form 6 September 2017

\begin{abstract}
A novel gold/aniline-pentamer-based electroactive polyamide (Au/EPA) composites that can modify carbon paste electrodes (CPEs) for ascorbic acid (AA) sensing has been studied in detail in this article. Cyclic voltammetry studies indicated improved electrochemical properties of the Au/EPA composites, demonstrating the occurrence of efficient electron/ charge transfer between the Au and the EPA. Experimental tests shows that there is a linear relationship between the concentration of added AA and the response current for the CPE modified with Au/EPA sensor to the concentration of AA in the range of $0.05-0.75 \mathrm{mM}\left(R^{2}=0.996, n=15\right)$. The detection limit and the sensitivity of the Au/EPA-CPE AA sensors were $2.75 \mu \mathrm{M}$ at a signal to noise ratio $(S / N)$ of 3 , and $21.7 \mathrm{~mA} \cdot \mathrm{mM}^{-1}$, respectively.
\end{abstract}

Keywords: polymer composites, electroactive polymer, electrochemical sensing

\section{Introduction}

Recently, electroactive polymers incorporated with aniline oligomers have attracted research attention because of their superior properties such as good solubility, biodegradable properties and the ability to form films [1-5]. These synthetic strategies include post polymerization grafting of oligoanilines onto the polymer chain, polycondensation of reactive monomers containing oligoanilines to form polymers, and oxidative coupling polymerization to form oligoaniline segments during polymerization [6]. Chao and Wang synthesized a series of electroactive polymers which bear oligoaniline, phenylamine, and fluorene groups in their side chain [7-9]. The generated fluorescence showed a clear multiple stimuli-responsive behavior against redox species,
$\mathrm{pH}$, electricity, and pressure, contributed by the sensitive oligoaniline and phenylamine groups. Zagorska and co-workers prepared electroactive polymers combining the electrochromic properties of polythiophenes and oligoanilines $[10,11]$. Both the polythiophene main chains and the oligoaniline side chains could be doped in various ways.

Yeh and coworkers synthesized a series of electroactive polymers such as epoxy [12], polyimide [13, 14], polyurea [15], and polyamide [16] as anticorrosion coating materials. The mechanism for the enhanced corrosion protection ability of the electroactive polymer coatings could be attributed to the formation of passive metal oxide layers on the metal electrode surface, which was induced by the redox catalytic capabilities of the aniline oligomer $[17,18]$. 
Most recently, many studies have used electroactive polymers as sensing materials. The acid-base doping/dedoping chemistry and redox properties of electroactive polymers have indicated their potential to be used as ammonia sensors [19], glucose [20] and fluorescent sensors [21].

Potentiometric detection method based on ion selective electrode is a simple method with many advantages, including ease to use and quick response time. Compared with the optical detection method, it is less susceptible to solution color or turbidity [22]. Modified carbon paste electrodes by chemical procedure, in all kinds of ion selection electrodes, are widely used in electrochemistry field. Carbon paste matrix possesses superior features such as easy preparation, renewability through simple polishing, uniformly disperse modified substance in the carbon paste, good reproducibility and stability and low ohmic resistance $[23,24]$.

Ascorbic acid (AA, vitamin C) is one of the important nutrients for human body, and the lack of AA in the human body leads to scurvy [25, 26]. Clinical studies have shown that the concentration of ascorbic acid in the biological fluid could be utilized to assess the amount of oxidative stress in human metabolism $[27,28]$. AA is needed for healing wounds, and for repairing and maintaining bones and teeth. Low levels of AA have been associated with a number of conditions, including high blood pressure, stroke, Parkinson's disease, some cancers, and atherosclerosis [29, 30]. Several techniques have been reported for the determination of AA, including electrochemical, optical, and chromatographic methods [31-34]. Electrochemical methods are considered as one of the best potential approaches because of their high sensitivity and simplicity.

Huang and coworkers [31, 35] used electroactive polymers to modify the carbon paste electrode (CPE) as ascorbic acid sensors. To enhance the detection limit of these CPE sensors, carbon nanotubes (CNTs) were incorporated into electroactive polymers. The facilitation of charge transfer processes between the two components significantly improved the properties of the sensors [36, 37].

In this study, the Au nanoparticles (NPs) were incorporated into electroactive polyamide (EPA) for the first time. The amine (-NH-) group on the EPA main chains can anchor Au NPs and improve the charge transfer in $\mathrm{Au} / \mathrm{EPA}$ composites, thus enhancing the sensing performance [38]. The images of transmission electron microscopy (TEM) show that Au NPs can be dispersed very well in EPA. The results of the cyclic voltammetry (CV) studies indicated that $\mathrm{Au}$ can enhance the current value of the Au/EPA composites. The sensitivity was significantly increased to $21.7 \mu \mathrm{A} / \mathrm{mM}$ for $\mathrm{Au} / \mathrm{EPA}-\mathrm{CPE}$ compared to $5.13 \mu \mathrm{A} / \mathrm{mM}$ for EPA-CPE.

\section{Experimental}

\subsection{Materials and instrumentation}

Glutaryl chloride (Aldrich), $N$-phenyl-p-phenylenediamine (NPPD, Aldrich), Triethylamine (Tedia), Dichloromethane (Shimakyu's Pure Chemicals), $p$ Phenylenediamine (PPD, Aldrich), Tetrachloroauric (III) acid trihydrate (Acros), $N$-Methyl-2-pyrrolidone (NMP, Merck), Hydrochloric acid (HCl, Showa), Ammonium persulfate (APS, Merck), Sodium Borohydride (Acros) were used as received without further purification. Fourier-transform infrared (FTIR) spectra were collected at room temperature (on a Shimadzu IRAffinity-1S spectrometer, Japan). UV-Vis absorption spectra was collected using a UV-Vis spectrometer (Jasco V-750, Japan). The morphological characterizations were observed by scanning electron microscope (SEM, JEOL JSM-7100F, Japan) and a transmission electron microscopy (TEM, JEOL JEM-1400, Japan). The X-ray diffraction (XRD) analyse was carried out by PANalytical X'Pert ${ }^{3}$ Powder diffractometer. Electrochemical experiments were performed on a CHI 6273E electrochemical analyzer using a conventional three-electrode system.

\subsection{Synthesis of EPA and Au/EPA composites}

\subsubsection{Synthesis of oligoaniline and EPA}

Glutaryl chloride (1.324 g, 7.8 mmole) was dissolved in dichloromethane $(20 \mathrm{~mL})$ and then introduced dropwise over a period of $1 \mathrm{~h}$ into a stirred solution of triethylamine $(0.2 \mathrm{~mL})$ and $N$-phenyl-p-phenylenediamine ( $2.873 \mathrm{~g}, 15.6 \mathrm{mmole}$ ) dissolved in dichloromethane $(15 \mathrm{~mL})$. The solution was magnetically stirred for $3 \mathrm{~h}$ and the electroactive oligoaniline was precipitated as a fine gray particulate. The prepared oligoaniline was then filtered, washed with an excess amount of dichloromethane several times, and finally dried at room temperature for $24 \mathrm{~h}$. The gray-green powder was obtained in a yield of approximately 95\%. FTIR (KBr, cm $\left.{ }^{-1}\right): 3313\left(\mathrm{~s}, \mathrm{v}_{\mathrm{NH}}\right), 2886\left(\mathrm{w}, \mathrm{v}_{\mathrm{CH}}\right)$, 1650 (versus, $v_{\mathrm{C}=\mathrm{O}}$ ), 1602 ( $\mathrm{s}, \mathrm{v}_{\mathrm{C}=\mathrm{C}}$ of quinoid rings), 1515 (versus, $v_{\mathrm{C}=\mathrm{C}}$ of benzenoid rings), 1316 (s, $\left.\delta_{\mathrm{C}-\mathrm{N}}\right), 823\left(\mathrm{~m}, \delta_{\mathrm{CH}}\right) .{ }^{1} \mathrm{H}-\mathrm{NMR}\left(d_{6}\right.$-DMSO): $\delta=9.747$ 
$(\mathrm{s}, 2 \mathrm{H},-\mathrm{NH}), \delta=7.985(\mathrm{~s}, 2 \mathrm{H},-\mathrm{NH}), \delta=7.458(\mathrm{~d}$, $4 \mathrm{H}, \mathrm{Ar}-\mathrm{H}), \delta=7.167$ (t, 4H, Ar-H), $\delta=6.95 \sim 7.01$ $(\mathrm{m}, 8 \mathrm{H}, \mathrm{Ar}-\mathrm{H}), \delta=6.73(\mathrm{t}, 2 \mathrm{H}, \mathrm{Ar}-\mathrm{H}), \delta=2.32(\mathrm{t}$, $\left.4 \mathrm{H},-\mathrm{CH}_{2}\right), \delta=1.88\left(\mathrm{~m}, 2 \mathrm{H},-\mathrm{CH}_{2}\right)$.

EPA was prepared by simultaneously dissolving oligoaniline (1 g, 2 mmole) and 1,4-phenylenediamine $(0.216 \mathrm{~g}, 2 \mathrm{mmole})$ into $20 \mathrm{~mL}$ of a stirring solution that contained $20 \mathrm{~mL}$ of NMP, $2 \mathrm{~mL}$ of distilled water, and $2 \mathrm{~mL}$ of concentrated hydrochloric acid. Subsequently, a solution containing $0.456 \mathrm{~g}$ of APS and $1.5 \mathrm{~mL}$ of $1.0 \mathrm{M}$ aqueous $\mathrm{HCl}$ was added dropwise while stirring at room temperature. The resulting solution was allowed to react for another $24 \mathrm{~h}$. Then the EPA was precipitated by pouring the obtained solution into $150 \mathrm{~mL}$ of distilled water. The precipitate was filtered and washed with distilled water and acetone several times. The obtained product was then freeze dried for $24 \mathrm{~h}$. The deep green powder of EPA was obtained in a yield of approximately $62.4 \%$. A detailed synthesis process was described in a previous study [16]. FTIR $\left(\mathrm{KBr}, \mathrm{cm}^{-1}\right)$ : $3300\left(\mathrm{~s}, v_{\mathrm{NH}}\right), 3041\left(\mathrm{w}, v_{\mathrm{CH}}\right), 1658$ (versus, $v_{\mathrm{C}=\mathrm{O}}$ ), $1596\left(\mathrm{~s}, v_{\mathrm{C}=\mathrm{C}}\right.$ of quinoid rings), 1511 (versus, $v_{\mathrm{C}=\mathrm{C}}$ of benzenoid rings), $1305\left(\mathrm{~s}, \delta_{\mathrm{C}-\mathrm{N}}\right), 829\left(\mathrm{~m}, \delta_{\mathrm{CH}}\right)$.

\subsubsection{Synthesis of Au/EPA composites}

$\mathrm{HAuCl}_{4}$ aqueous solution ( $1 \mathrm{mM}, 15 \mathrm{~mL}$ ) and EPA (30 mg) were vigorously stirred. Rapid addition of sodium borohydride aqueous solution $(1.5 \mathrm{M}$, $300 \mu \mathrm{L}$ ) to the solution resulted in a color change from pale yellow to wine red. The solution was magnetically stirred for $6 \mathrm{~h}$, then the prepared compound was filtered and washed with deionized water several times. The Au/EPA composites were obtained after freeze drying for $24 \mathrm{~h}$ in powdered form. The synthesis route for $\mathrm{Au} / \mathrm{EPA}$ composites is presented in Figure 1.
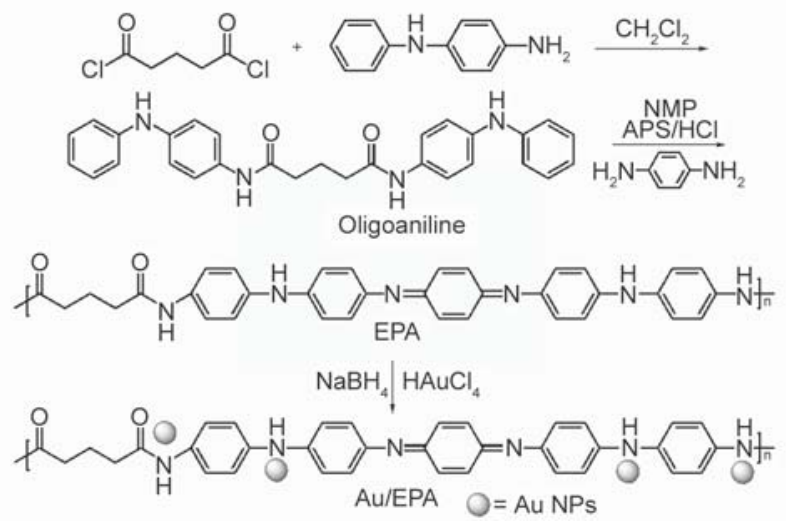

Figure 1. The synthesis route of the oligoaniline, EPA and $\mathrm{Au} / \mathrm{EPA}$ composites

\subsection{Testing chemical oxidation of EPA by UV-visible absorption spectroscopy}

The synthesized EPA composites $(0.5 \mathrm{~g})$ were dispersed into a solution containing $5 \mathrm{~mL}$ hydrazine hydrate $\left(\mathrm{N}_{2} \mathrm{H}_{4}\right)$ in $50 \mathrm{~mL} 1.0 \mathrm{M}$ ammonium hydroxide $\left(\mathrm{NH}_{4} \mathrm{OH}\right)$ and was stirred for $24 \mathrm{~h}$. The reaction mixture was then filtered, washed with distilled water several times, and dried under dynamic vacuum at $40^{\circ} \mathrm{C}$ for $24 \mathrm{~h}$. Finally, the EPA was reduced to the leucoemeraldine oxidation state $(0.43 \mathrm{~g}, 86 \%)$. The leucoemeraldine base (LB) form of the EPA was dissolved in an NMP solution. Subsequently, trace amounts of the oxidant, $\left(\mathrm{NH}_{4}\right)_{2} \mathrm{~S}_{2} \mathrm{O}_{8}$, were introduced into the EPA solution gradually for in-situ monitoring of the sequential oxidation process of the conjugated aniline oligomer components by UV-Visible absorption spectroscopy.

\subsection{Preparation of the EPA and Au/EPA modified CPE}

A modified electrode was prepared by carefully homogenizing a mixture of graphite powder $(150 \mathrm{mg}$, $80 \%$ ), EPA or Au/EPA (7.5 mg, 4\%) and paraffin oil (30 mg, 16\%). A portion of the carbon paste was firmly packed into one end of a Teflon tube $(\sim 3.0 \mathrm{~mm}$ internal diameter) and a copper wire was inserted through the opposite end to establish an electrical contact. Appropriate packaging was achieved by pressing the surface against a bond paper until a smooth surface was obtained, as illustrated in Figure 2. The total mass of graphite and the Au/EPA composites was set to $30 \mathrm{mg}$.

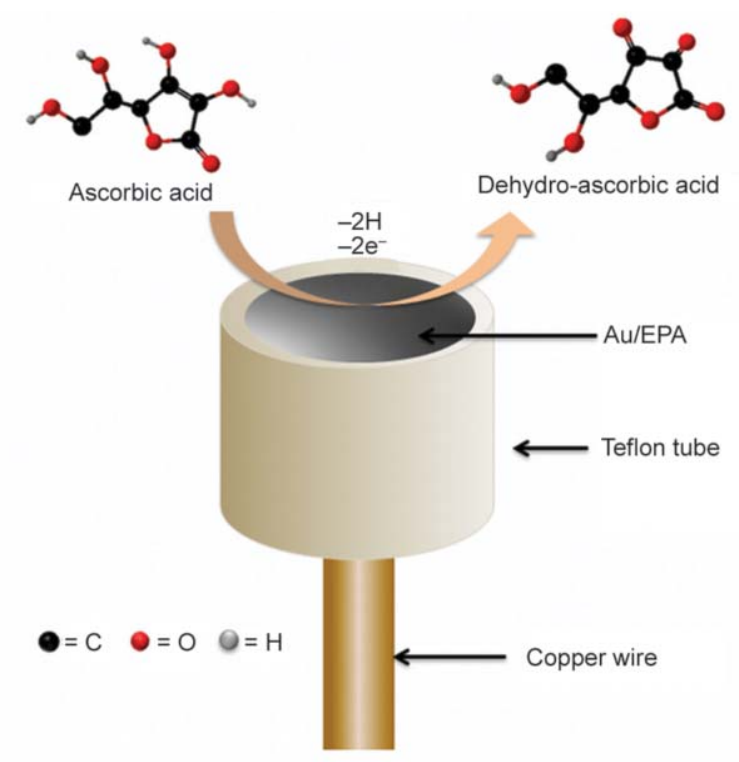

Figure 2. The fabrication scheme for carbon paste electrode 


\section{Results and discussion}

\subsection{Chemical oxidation of EPA}

In Figure 3 the peak at $319 \mathrm{~nm}$ was associated with the $\pi$ to $\pi^{*}$ transition of the conjugated ring system [39]. Upon the addition of trace amounts of the oxidant, slow oxidation of the aniline pentamer segments in EPA was observed. The original absorption band detected by UV-Visible spectroscopy underwent a blue shift from 319 to $308 \mathrm{~nm}$, accompanied with a decrease in intensity. At the same time, a new absorption peak appeared at $588 \mathrm{~nm}$, which was designated to the exciton-type transition between the HOMO orbital of the benzoid ring and the LUMO orbital of the quinoid ring [40]. After the intensity reached a maximum value for the second absorption peak, it began to undergo a blue shift from 588 to $570 \mathrm{~nm}$. One possible interpretation of this result is presented as follows. During the continuous oxidation of EPA in the LB oxidation state, the EPA first converted to the emeraldine oxidation base state (EB I) with each aniline pentamer segment containing only one quinoid ring, which showed a second absorption at a longer wavelength. Subsequently, it was oxidized to the second emeraldine oxidation base state (EB II) with each aniline pentamer segment containing two quinoid rings, which corresponded with the increase in intensity of the second absorption peak. After the second absorption peak reached maximum intensity, it exhibited a blue shift. This blue shift is indicative of the conversion past the emeraldine base state to the pernigraniline base state (PNB) [41, 42].

\subsection{XRD measurement}

The XRD patterns of the synthesized EPA (Figure 4 curve a) show a broad peak, which is characteristic of the diffraction by the chain periodicity of EPA polymer [43].

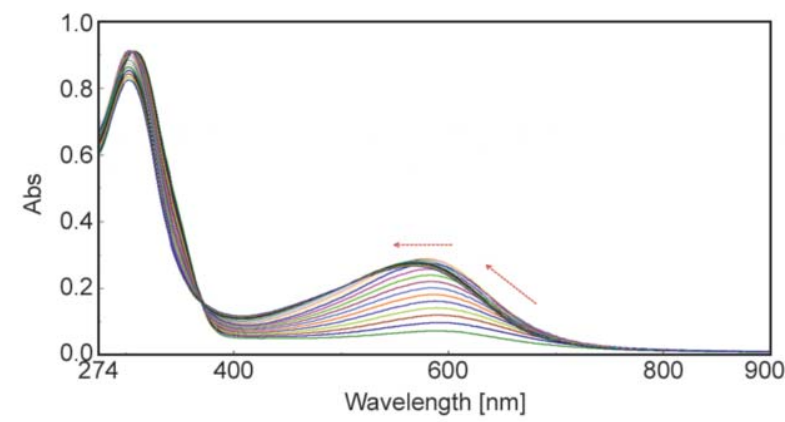

Figure 3. UV-Vis spectra monitoring the chemical oxidation of the $\mathrm{Au} / \mathrm{EPA}$ composites in the leucoemeraldine oxidation state
The diffraction pattern in Figure 4 curve $b$ is in good agreement with face-centered cubic structure of metallic gold (JCPDS: 04-0784) [25, 44].The peaks at $38.17,44.28,64.61$ and $77.72^{\circ}$ are assigned to facecentered cubic bulk Au (111), (200), (220) and (311), respectively $[45,46]$. The crystallite size is calculated by Debye-Scherrer formula [47]: $D=K \lambda / \beta \cos \theta$, where $D$ is the particle size, $K$ is the Scherrer constant (shape factor), $\lambda$ is the wavelength of the X-ray, $\beta$ is the full width half maximum (FWHM), $\theta$ is the Braggle angle. The average size of Au deduced from the XRD profiles of the Au/EPA samples was found to be $7.6 \mathrm{~nm}$ by Scherrer equation. The result shows that $\mathrm{Au}$ NPs has been anchored on EPA.

\subsection{SEM and TEM analyses}

Figure 5 shows the SEM images of EPA and $\mathrm{Au} / \mathrm{EPA}$ composite. Figure $5 \mathrm{~b}$ is the morphology of $\mathrm{Au} / \mathrm{EPA}$ composite. Compared to Figure $5 \mathrm{a}$, the $\mathrm{Au}$ NPs can be clearly observed in Figure 5b. This indicate that the Au NPs were dispersed very well in EPA. To further confirm the element on the EPA, Figure $5 c$ reveals the EDS mapping including $C, N$, $\mathrm{O}$ and $\mathrm{Au}$ elements. The $\mathrm{C}, \mathrm{N}, \mathrm{O}$ element peaks comes from the chemical structure of EPA and the $\mathrm{N}$ elemental peak corresponds to the structure of EPA responsible for anchoring the Au NPs [38, 48]. Au elemental-mapping images confirm the uniform distribution of Au NPs on the EPA. TEM is used to investigate three-dimensional morphological images of the prepared hybrid matrices. Figure $5 \mathrm{~d}$ demonstrates that $\mathrm{Au} / \mathrm{EPA}$ hybrid material exhibited a good dispersion of $\mathrm{Au}$ with $<10 \mathrm{~nm}$ in diameter existed in hybrid matrix.

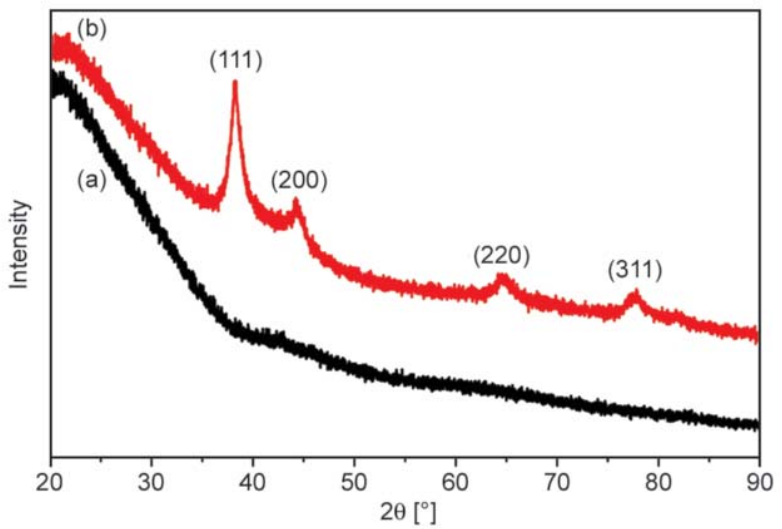

Figure 4. XRD patterns of (a) EPA and (b) Au/EPA composites 


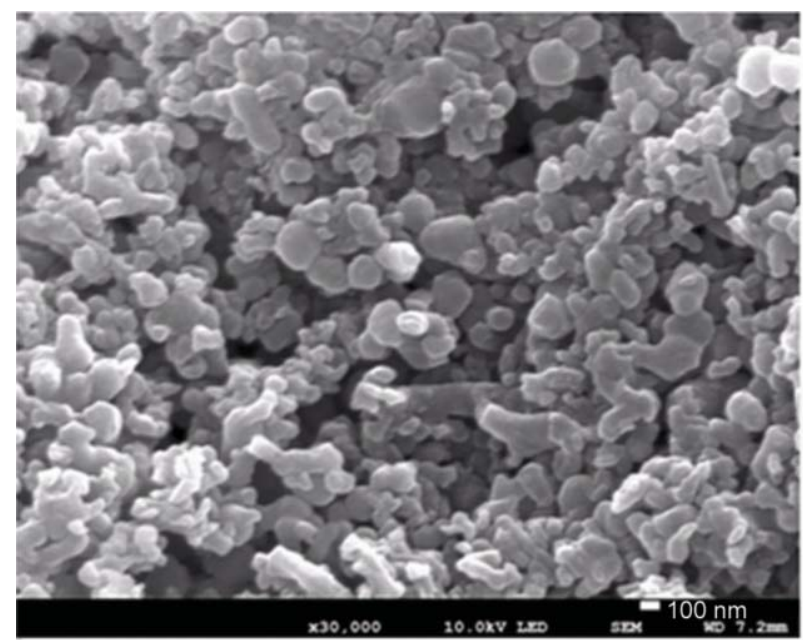

a)
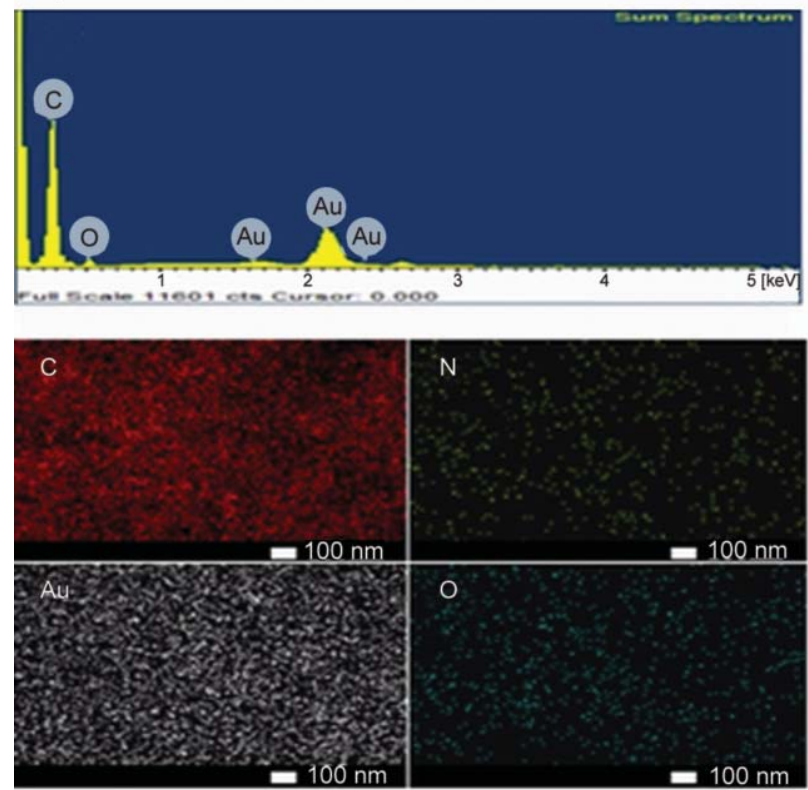

c)

Figure 5. SEM images of (a) EPA and (b) Au/EPA composites (Arrows indicate gold nanoparticles), (c) EDS results of the corresponding images of Au/EPA composites, (d) TEM image of Au/EPA composites

\subsection{Electroactivity of EPA-CPE and Au/EPA-CPE}

CV has been widely used to characterize the electrochemical properties of electroactive polymers. In this study, the electrochemical properties of the EPA and $\mathrm{Au} / \mathrm{EPA}$ composite were characterized by $\mathrm{CV}$ using a three-electrode electrochemical cell. The CV experiments were carried out in $1.0 \mathrm{M} \mathrm{H}_{2} \mathrm{SO}_{4}$ at a scan rate of $50 \mathrm{mV} \cdot \mathrm{s}^{-1}$. Both EPA and $\mathrm{Au} / \mathrm{EPA}$ composites showed three pairs of redox peaks with oxidation peaks at 380,563 , and $736 \mathrm{mV}$, which are leucoemeraldine base (LB) to emeraldine base I (EB I), EB I to emeraldine base II (EB II), and EB II to pernigraniline (PNB), respectively (Figure 6a). Four different oxidation states of EPA can be found: LB, EBI (one quinoid ring in oligoaniline segment), EBII

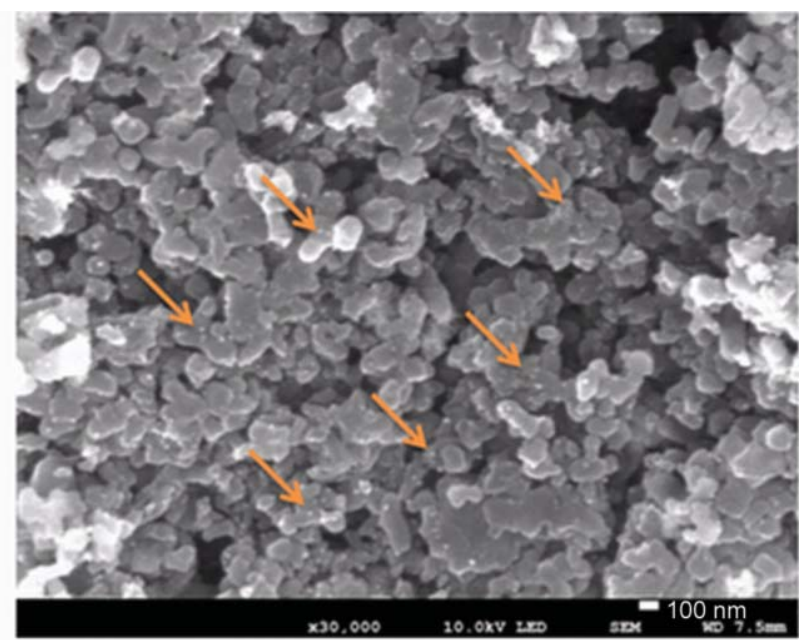

b)

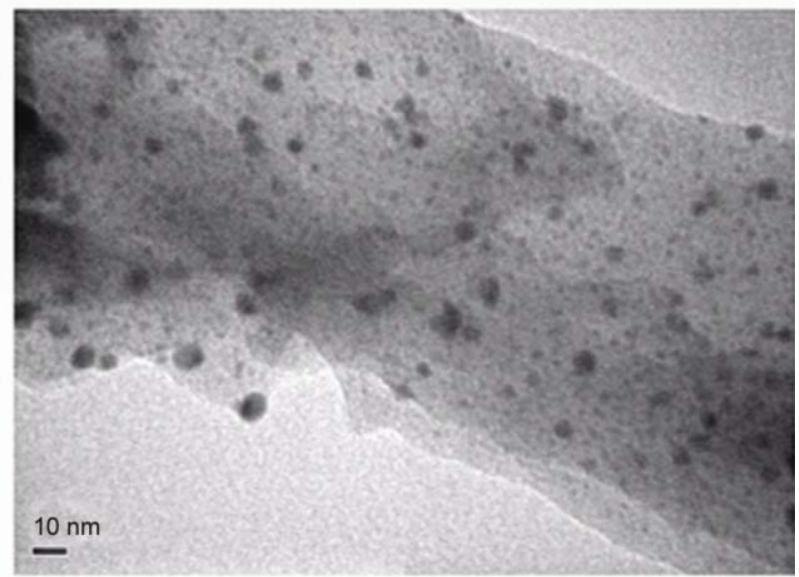

d) (two quinoid rings in oligoaniline segment), and PNB, as shown in Figure 6c.

Comparing EPA with the Au/EPA composites, the introduction of Au into EPA caused a shift of the oxidation peaks towards higher currents. In addition, the significant improvement in the value of the current suggests much more effective electron inclusion and exclusion during the redox processes in the $\mathrm{Au} / \mathrm{EPA}$ composites than in the neat EPA. In Figure $6 \mathrm{~b}$, the $\mathrm{CV}$ responses for the Au/EPA-CPE were recorded at different scan rates ranging from 25 to $150 \mathrm{mV} / \mathrm{s}$. As higher scan rates were applied, the oxidative peak potentials shifted to positive potential, and the reductive peak potentials shifted toward negative potential. A linear dependence of the peak currents as a function of scan rate in the region of 

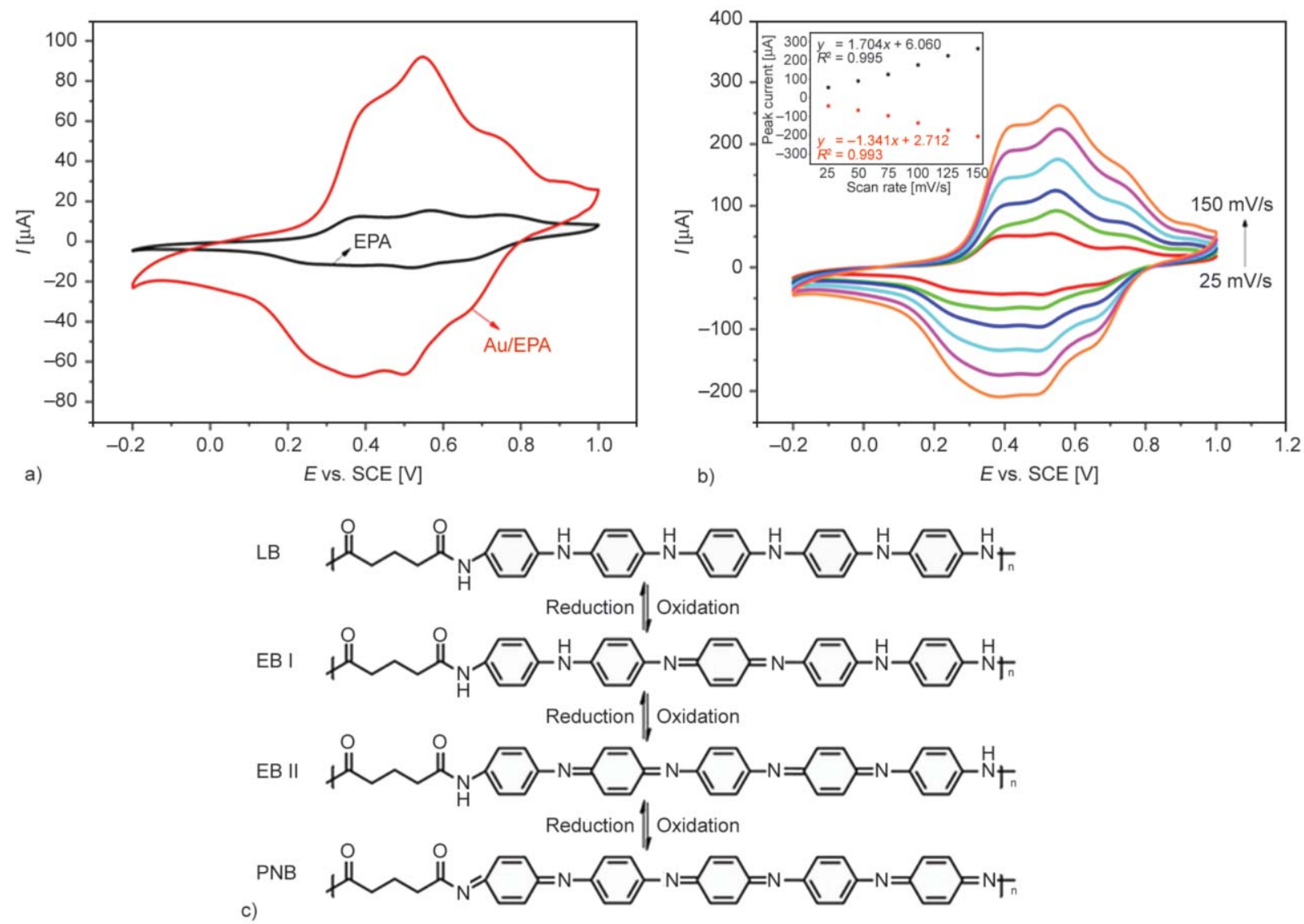

Figure 6. Representative CV curves of the (a) EPA and Au/EPA-CPE in $\mathrm{pH} 7.0 \mathrm{PBS}$ solution. Scan rate: $50 \mathrm{mV} / \mathrm{s}$. (b) $\mathrm{Au} / \mathrm{EPA}-\mathrm{CPE}$ in $1 \mathrm{M} \mathrm{H}_{2} \mathrm{SO}_{4}$ at different potential scan rates: 25, 50, 75, 100, 125 and $150 \mathrm{mV} / \mathrm{s}$. Inset: plot of peak current versus square root of the scan rate. (c) Molecular structures of EPA at various oxidation states.

$25-150 \mathrm{mV} / \mathrm{s}$ confirmed both a surface controlled process [49-51].

\subsection{Electrochemical response of Au/EPA-CP E toward ascorbic acid}

Figure 7 shows the $\mathrm{CV}$ curves of Au/EPA-CPE acquired at $50 \mathrm{mV} \cdot \mathrm{s}^{-1}$ with the continuous addition of ascorbic acid (AA) into PBS solution at $\mathrm{pH}$ 7.0. The AA concentrations in the buffer ranged from 0.0 to $8.0 \mathrm{mM}$. The current (oxidation peak, which occurred at $0.3 \mathrm{~V}$ versus $\mathrm{Ag} / \mathrm{AgCl}$ ) which increased with the concentration of AA, corresponded to the catalytic properties of AA at the modified electrode. The inset shows the max currents plotted versus amount of AA added. A linear relationship was observed for concentration of AA beyond the 0.0 $8.0 \mathrm{mM}$ range used $\left(R^{2}=0.997, n=5\right)$.

Figure 8 shows the amperometric response of EPA$\mathrm{CPE}$ and $\mathrm{Au} / \mathrm{EPA}-\mathrm{CPE}$ with the continuous addition of AA in the buffer solution. Each step current observed represents an increase by $100 \mathrm{mM}$ of AA $(20 \mu \mathrm{L})$. There was a linear relationship between the concentration of AA added and the peak current

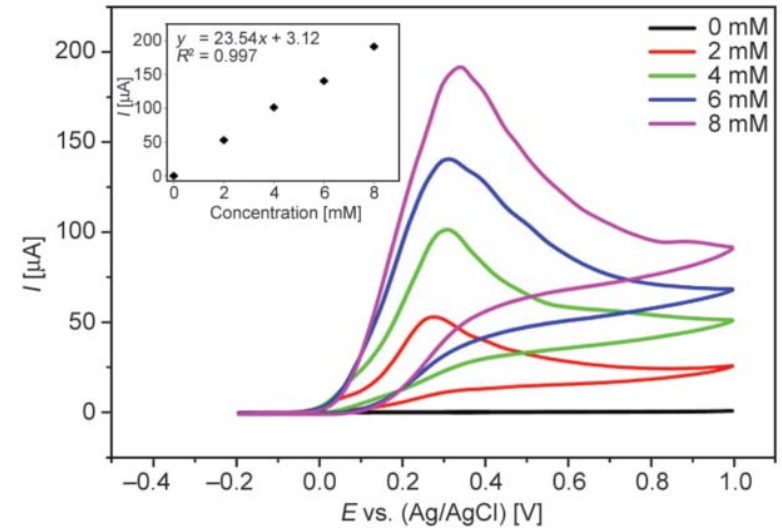

Figure 7. CV curves of Au/EPA-CPE in pH 7.0 PBS solution with different AA concentrations

obtained, as evidenced by the linear calibration curve of the amperometric response of the sensor to the concentration of AA provided in the inset $\left(R^{2}=0.996\right.$ for EPA-CPE and $R^{2}=0.995$ for Au/EPA-CPE, $n=$ 15). Moreover, the response current of Au/EPA-CPE was larger than that of EPA-CPE. The high current response in Figure 8 curve $b$ may be attributed to the charge transfer processes between the Au NPs and EPA [52-54]. The detection limit decreased from 




Figure 8. Amperometric current responses of (a) EPA-CPE and (b) Au/EPA-CPE toward successive addition of AA into a $40 \mathrm{~mL}$ PBS ( $\mathrm{pH}$ 7.0) solution stirred constantly at a potential of $0.3 \mathrm{~V}$. The inset shows the calibration curve between the current and the concentration of AA.

$3.51 \mu \mathrm{M}$ for EPA-CPE AA sensor to $2.75 \mu \mathrm{M}$ for $\mathrm{Au} /$ EPA-CPE AA sensor at a $S / N$ (signal to noise ratio) of 3. The sensitivity increased from $5.13 \mu \mathrm{A} / \mathrm{mM}$ for EPA-CPE AA sensor to $21.7 \mu \mathrm{A} / \mathrm{mM}$ for Au/EPACPE AA sensor. These results also confirmed that the Au/EPA-CPE AA sensor was more sensitive than the EPA-CPE AA sensor. The sensitivity and the detection limit of the Au/EPA-CPE comparable to those of most modified electrodes reported in literature (Table 1). The sensitivity and the detection limit observed in the present study were higher than that observed in most other reports in literature.

We utilized dopamine (DA) as the interfering substance to test the performance of the developed sensors since the DA usually coexists with AA in biological samples.

The amperometric responses of DA was tested in the normal physiological concentration of $100 \mathrm{nM}$ DA [47]. Figure 9 shows the amperometric current response of $\mathrm{Au} / \mathrm{EPA}-\mathrm{CPE}$ to successive additions of $100 \mathrm{mM}$ AA and $1 \mathrm{mM}$ DA in PBS (pH 7.0) at the applied potential of $0.3 \mathrm{~V}$ vs. $\mathrm{Ag} / \mathrm{AgCl}$. No increase of current response was observed as adding DA. In contrast, adding the same amount of AA to the solution significantly increased the current. These results

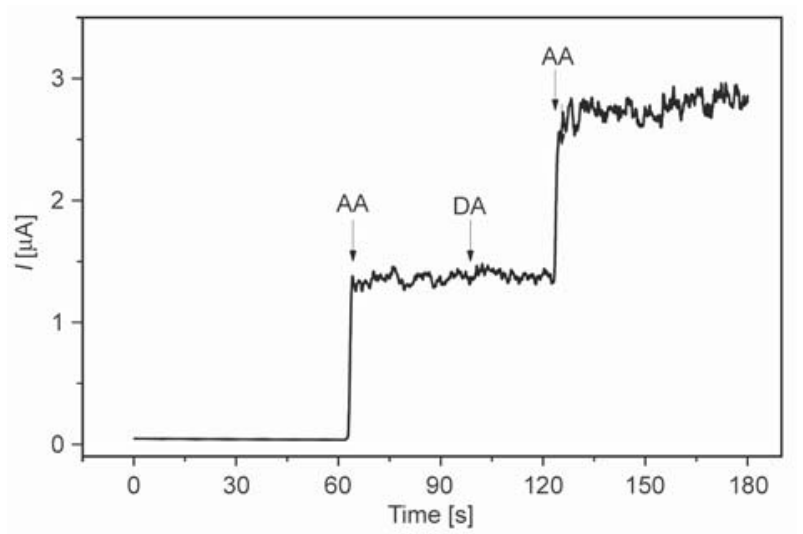

Figure 9. Amperometric response of the Au/EPA-CPE to successive additions of $100 \mathrm{mM}$ AA, $1 \mathrm{mM}$ DA with stirring in PBS ( $\mathrm{pH} 7.0$ ) at a potential of $0.3 \mathrm{~V}$

Table 1. A comparison of various types of ascorbic acid sensors

\begin{tabular}{|c|c|c|c|c|}
\hline Modified electrode & $\begin{array}{c}\text { Applied potential } \\
\text { [V] }\end{array}$ & $\begin{array}{c}\text { Detection limit } \\
{[\mu \mathrm{M}]}\end{array}$ & $\begin{array}{l}\text { Sensitivity } \\
{\left[\mu \mathrm{A} \cdot \mathbf{m M}^{-1}\right]}\end{array}$ & Reference \\
\hline EPI-CPE & 0.400 & 9.60 & ${ }^{a} \mathrm{NR}$ & {$[31]$} \\
\hline EPU-CPE & 0.420 & 6.10 & 15.40 & [35] \\
\hline $\mathrm{Au} / \mathrm{RGO}-\mathrm{GCE}$ & ${ }^{a} \mathrm{NR}$ & 51.00 & ${ }^{\mathrm{a}} \mathrm{NR}$ & [47] \\
\hline FCAM-CPE & 0.248 & 10.80 & ${ }^{\mathrm{a} N R}$ & [55] \\
\hline CoTNPPc/MWNTs-GCE & 0.215 & 5.00 & ${ }^{a} \mathrm{NR}$ & {$[56]$} \\
\hline DBSA/doped-CPE & 0.000 & 8.30 & 10.75 & {$[57]$} \\
\hline $\mathrm{SiO}_{2} / \mathrm{AuNP} / \mathrm{PANI} / \mathrm{CS}-\mathrm{GCE}$ & 0.384 & 6.00 & ${ }^{a} \mathrm{NR}$ & {$[58]$} \\
\hline PG-GCE & ${ }^{\mathrm{a} N \mathrm{NR}}$ & $6.45 \pm 0.23$ & ${ }^{\mathrm{a} N R}$ & [59] \\
\hline Chitosan/GR-GCE & ${ }^{\mathrm{a} N \mathrm{NR}}$ & 50.00 & ${ }^{\mathrm{a} N R}$ & {$[60]$} \\
\hline EPA-CPE & 0.350 & 3.51 & 5.13 & This work \\
\hline $\mathrm{Au} / \mathrm{EPA}-\mathrm{CPE}$ & 0.300 & 2.75 & 21.70 & This work \\
\hline
\end{tabular}

$\begin{array}{ll}\text { EPI } & - \text { electroactive polyimide } \\ \text { EPU } & - \text { electroactive polyurea } \\ \text { FCAM } & - \text { ferrocene carboxylic acid } \\ \text { CoTNPPc } & \text { - cobalt(II) tetra-neopentyloxy phthalocyanine } \\ \text { DBSA } & - \text { dodecylbenzene sulphonic acid } \\ \text { CS } & - \text { chitosan } \\ \text { PG } & - \text { pristine graphene }\end{array}$




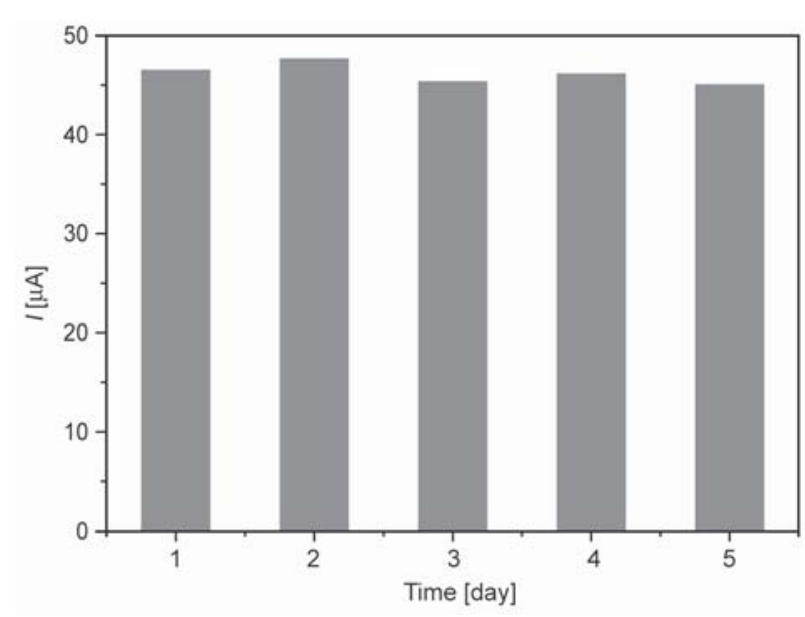

Figure 10. The repeatability of proposed sensor for five successive measurements in $2 \mathrm{mM}$ AA

confirm that presence of DA did not interfere with AA peak current.

To further study the stability of Au/EPA-CPE, the electrode was well preserved at PBS solution $\left(4^{\circ} \mathrm{C}\right)$ and was used to detect $2 \mathrm{mM}$ of AA multiple times. In Figure 10, the current response did not significantly decrease in each successive measurement. The AA sensor showed good repeatability for the measurement of $2 \mathrm{mM}$ AA with minimal relative standard deviation of $2.23 \%$. This means that Au/EPA-CPE is stable and can perform repeatable and reliable AA sensing.

\section{Conclusions}

This work demonstrates the fabrication and performance of Au/EPA-CPE as AA sensors. The TEM image shows that Au NPs disperse very well in EPA and the $\mathrm{CV}$ reveals the $\mathrm{Au} / \mathrm{EPA}-\mathrm{CPE}$ exhibit higher current than EPA-CPE. This can be attributed to the higher charge transfer between Au and EPA material. Therefore, the electrocatalytic property of Au/EPA composites toward the oxidation of AA was significantly enhanced. According to the results, CPE modified with $\mathrm{Au} / \mathrm{EPA}$ electrode may have potential as an AA sensor in the future.

\section{Acknowledgements}

This research was supported by the Ministry of Science and Technology, R. O. C. (MOST-105-2221-E-239-031 and 1062221-E-167-033).

\section{References}

[1] Qu G., Li F., Berda E. B., Chi M., Liu X., Wang C., Chao D.: Electroactive polyurea bearing oligoaniline pendants: Electrochromic and anticorrosive properties. Polymer, 58, 60-66 (2015).

https://doi.org/10.1016/j.polymer.2014.12.033

[2] Jia X., Chao D., Liu H., He L., Zheng T., Bian X., Wang C.: Synthesis and properties of novel electroactive poly (amic acid) and polyimide copolymers bearing pendant oligoaniline groups. Polymer Chemistry, 2, 1300-1306 (2011).

https://doi.org/10.1039/C1PY00035G

[3] Cui H., Shao J., Wang Y., Zhang P., Chen X., Wei Y.: PLA-PEG-PLA and its electroactive tetraaniline copolymer as multi-interactive injectable hydrogels for tissue engineering. Biomacromolecules, 14, 1904-1912 (2013). https://doi.org/10.1021/bm4002766

[4] Cui H., Liu Y., Deng M., Pang X., Zhang P., Wang X., Chen X., Wei Y.: Synthesis of biodegradable and electroactive tetraaniline grafted poly(ester amide) copolymers for bone tissue engineering. Biomacromolecules, 13, 2881-2889 (2012). https://doi.org/10.1021/bm300897j

[5] Guo B., Glavas L., Albertsson A-C.: Biodegradable and electrically conducting polymers for biomedical applications. Progress in Polymer Science, 38, 1263-1286 (2013).

https://doi.org/10.1016/j.progpolymsci.2013.06.003

[6] Chao D., He L., Berda E. B., Wang S., Jia X., Wang C.: Multifunctional hyperbranched polyamide: Synthesis and properties. Polymer, 54, 3223-3229 (2013).

https://doi.org/10.1016/j.polymer.2013.04.021

[7] Yan Y., Sun N., Li F., Jia X., Wang C., Chao D.: Multiple stimuli-responsive fluorescence behavior of novel polyamic acid bearing oligoaniline, triphenylamine, and fluorene groups. ACS Applied Materials and Interfaces, 9, 6497-6503 (2017).

https://doi.org/10.1021/acsami.6b16402

[8] Yan Y., Jia X., Feng M., Wang C., Chao D.: Synthesis and electrochemical characterization of polyamic acid containing oligoaniline and triphenylamine. Journal of Polymer Science Part A: Polymer Chemistry, 55, 16691673 (2017).

https://doi.org/10.1002/pola.28545

[9] Sun N., Meng S., Chao D., Zhou Z., Du Y., Wang D., Zhao X., Zhou H., Chen C.: Highly stable electrochromic and electrofluorescent dual-switching polyamide containing bis(diphenylamino)-fluorene moieties. Polymer Chemistry, 7, 6055-6063 (2016). https://doi.org/10.1039/C6PY01345G 
[10] Buga K., Majkowska A., Pokrop R., Zagorska M., Djurado D., Pron A., Oddou J. L., Lefrant S.: Postpolymerization grafting of aniline tetramer on polythiophene chain: Structural organization of the product and its electrochemical and spectroelectrochemical properties. Chemistry of Materials, 17, 5754-5762 (2005). https://doi.org/10.1021/cm050794m

[11] Buga K., Pokrop R., Majkowska A., Zagorska M., Planes J., Genoud F., Pron A.: Alternate copolymers of head to head coupled dialkylbithiophenes and oligoaniline substituted thiophenes: Preparation, electrochemi$\mathrm{cal}$ and spectroelectrochemical properties. Journal of Materials Chemistry, 16, 2150-2164 (2006).

https://doi.org/10.1039/B516677M

[12] Huang T-C., Su Y-A., Yeh T-C., Huang H-Y., Wu C-P., Huang K-Y., Chou Y-C., Yeh J-M., Wei Y.: Advanced anticorrosive coatings prepared from electroactive epoxy- $\mathrm{SiO}_{2}$ hybrid nanocomposite materials. Electrochimica Acta, 56, 6142-6149 (2011).

https://doi.org/10.1016/j.electacta.2011.04.053

[13] Huang T-C., Yeh T-C., Huang H-Y., Ji W-F., Chou Y-C., Hung W-I., Yeh J-M., Tsai M. H.: Electrochemical studies on aniline-pentamer-based electroactive polyimide coating: Corrosion protection and electrochromic properties. Electrochimica Acta, 56, 10151-10158 (2011). https://doi.org/10.1016/j.electacta.2011.08.114

[14] Chou Y-C., Lee P-C., Hsu T-F., Huang W-Y., Li Z-H., Chuang C-Y., Yang T-I., Yeh J-M.: Synthesis and anticorrosive properties of electroactive polyimide/ $\mathrm{SiO}_{2}$ composites. Polymer Composites, 35, 617-625 (2014). https://doi.org/10.1002/pc.22703

[15] Yeh T-C., Huang T-C., Huang H-Y., Huang Y-P., Cai YT., Lin S-T., Yeh J-M.: Electrochemical investigations on anticorrosive and electrochromic properties of electroactive polyurea. Polymer Chemistry, 3, 2209-2216 (2012).

https://doi.org/10.1039/C2PY20061A

[16] Huang T-C., Yeh T-C., Huang H-Y., Ji W-F., Lin T-C., Chen C-A., Yeh J-M.: Electrochemical investigations of the anticorrosive and electrochromic properties of electroactive polyamide. Electrochimica Acta, 63, 185 191 (2012).

https://doi.org/10.1016/j.electacta.2011.12.087

[17] Huang H-Y., Huang T-C., Lin J-C., Chang J-H., Lee YT., Yeh J-M.: Advanced environmentally friendly coatings prepared from amine-capped aniline trimer-based waterborne electroactive polyurethane. Materials Chemistry and Physics, 137, 772-780 (2013). https://doi.org/10.1016/j.matchemphys.2012.09.063

[18] Grgur B. N.: On the role of aniline oligomers on the corrosion protection of mild steel. Synthetic Metals, 187, 57-60 (2014).

https://doi.org/10.1016/j.synthmet.2013.10.019
[19] Wang S., Chao D., Berda E. B., Jia X., Yang R., Wang X., Jiang T., Wang C.: Fabrication of electroactive oligoaniline functionalized poly(amic acid) nanofibers for application as an ammonia sensor. RSC Advances, 3, 4059-4065 (2013).

https://doi.org/10.1039/C3RA00056G

[20] Yehezkeli O., Yan Y-M., Baravik I., Tel-Vered R., Willner I.: Integrated oligoaniline-cross-linked composites of au nanoparticles/glucose oxidase electrodes: A generic paradigm for electrically contacted enzyme systems. Chemistry A European Journal, 15, 2674-2679 (2009).

https://doi.org/10.1002/chem.200801609

[21] Wang S., Berda E., Lu X., Li X., Wang C., Chao D.: Tuning the fluorescent response of a novel electroactive polymer with multiple stimuli. Macromolecular Rapid Communications, 34, 1648-1653 (2013). https://doi.org/10.1002/marc. 201300448

[22] Nezamzadeh-Ejhieh A., Nematollahi Z.: Surfactant modified zeolite carbon paste electrode (SMZ-CPE) as a nitrate selective electrode. Electrochimica Acta, 56, 8334-8341 (2011).

https://doi.org/10.1016/j.electacta.2011.07.013

[23] Kalcher K., Kauffmann J. M., Wang J., Švancara I., Vytřas K., Neuhold C., Yang Z.: Sensors based on carbon paste in electrochemical analysis: A review with particular emphasis on the period 1990-1993. Electroanalysis, 7, 5-22 (1995).

https://doi.org/10.1002/elan.1140070103

[24] Nezamzadeh-Ejhieh A., Pouladsaz P.: Voltammetric determination of riboflavin based on electrocatalytic oxidation at zeolite-modified carbon paste electrodes. Journal of Industrial and Engineering Chemistry, 20, 21462152 (2014). https://doi.org/10.1016/j.jiec.2013.09.044

[25] Song J., Xu L., Xing R., Li Q., Zhou C., Liu D., Song $\mathrm{H}$.: Synthesis of Au/graphene oxide composites for selective and sensitive electrochemical detection of ascorbic acid. Scientific Reports, 4, 7515/1-7515/7 (2014). https://doi.org/10.1038/srep07515

[26] Pakapongpan S., Mensing J. P., Phokharatkul D., Lomas T., Tuantranont A.: Highly selective electrochemical sensor for ascorbic acid based on a novel hybrid graphene-copper phthalocyanine-polyaniline nanocomposites. Electrochimica Acta, 133, 294-301 (2014). https://doi.org/10.1016/j.electacta.2014.03.167

[27] Bijur G. N., Ariza M. E., Hitchcock C. L., Williams M. V.: Antimutagenic and promutagenic activity of ascorbic acid during oxidative stress. Environmental and Molecular Mutagenesis, 30, 339-345 (1997). https://doi.org/10.1002/(SICI)10982280(1997)30:3<339::AID-EM13>3.0.CO;2-E

[28] Koshiishi I., Imanari T.: Measurement of ascorbate and dehydroascorbate contents in biological fluids. Analytical Chemistry, 69, 216-220 (1997). https://doi.org/10.1021/ac960704k 
[29] Padayatty S. J., Katz A., Wang Y., Eck P., Kwon O., Lee J. H., Chen S., Corpe C., Dutta A., Dutta S. K., Levine M.: Vitamin $\mathrm{C}$ as an antioxidant: evaluation of its role in disease prevention. Journal of the American College of Nutrition, 22, 18-35 (2003).

https://doi.org/10.1080/07315724.2003.10719272

[30] Sharifian S., Nezamzadeh-Ejhieh A.: Modification of carbon paste electrode with Fe(III)-clinoptilolite nanoparticles for simultaneous voltammetric determination of acetaminophen and ascorbic acid. Materials Science and Engineering: C, 58, 510-520 (2016).

https://doi.org/10.1016/j.msec.2015.08.071

[31] Huang T-C., Lin S-T., Yeh L-C., Chen C-A., Huang HY., Nian Z-Y., Yeh J-M.: Aniline pentamer-based electroactive polyimide prepared from oxidation coupling polymerization for electrochemical sensing application. Polymer, 53, 4373-4379 (2012).

https://doi.org/10.1016/j.polymer.2012.07.064

[32] Park H. W., Alam S. M., Lee S. H., Karim M. M., Wabaidur S. M., Kang M., Choi J. H.: Optical ascorbic acid sensor based on the fluorescence quenching of silver nanoparticles. Luminescence, 24, 367-371 (2009). https://doi.org/10.1002/bio.1119

[33] Abbaspour A., Khajehzadeh A., Noori A.: A simple and selective sensor for the determination of ascorbic acid in vitamin $\mathrm{C}$ tablets based on paptode. Analytical Sciences, 24, 721-725 (2008).

https://doi.org/10.2116/analsci.24.721

[34] Sharafzadeh S., Nezamzadeh-Ejhieh A.: Using of anionic adsorption property of a surfactant modified clinoptilolite nano-particles in modification of carbon paste electrode as effective ingredient for determination of anionic ascorbic acid species in presence of cationic dopamine species. Electrochimica Acta, 184, 371-380 (2015).

https://doi.org/10.1016/j.electacta.2015.09.164

[35] Yeh L-C., Huang T-C., Huang Y-P., Huang H-Y., Chen H-H., Yang T-I., Yeh J-M.: Synthesis electroactive polyurea with aniline-pentamer-based in the main chain and its application in electrochemical sensor. Electrochimica Acta, 94, 300-306 (2013).

https://doi.org/10.1016/j.electacta.2013.01.073

[36] Huang T-C., Yeh L-C., Huang H-Y., Nian Z-Y., Yeh YC., Chou Y-C., Tsai M-H.: The use of a carbon paste electrode mixed with multiwalled carbon nanotube/ electroactive polyimide composites as an electrode for sensing ascorbic acid. Polymer Chemistry, 5, 630-637 (2014).

https://doi.org/10.1039/C3PY00787A

[37] Huang T. C., Yeh L. C., Lai G. H., Lai F. Y., Yang T. I., Huang Y. J., Yeh J. M.: Electroactive polyurea/CNT composite-based electrode for detection of vitamin C. Express Polymer Letters, 10, 450-461 (2016).

https://doi.org/10.3144/expresspolymlett.2016.43
[38] Yao H., Huang T-C., Sue H-J.: Self-assembly of Au nanoparticles on graphene sheets as a catalyst with controlled grafting density and high reusability. RSC Advances, 4, 61823-61830 (2014).

https://doi.org/10.1039/C4RA11231H

[39] Yeh L-C., Huang T-C., Lai F-Y., Lai G-H., Lo A-Y., Hsu S-C., Yeh J-M.: Synthesis of electroactive polyazomethine and its application in electrochromic property and electrochemical sensor. Surface and Coatings Technology, 303, 154-161 (2016).

https://doi.org/10.1016/j.surfcoat.2016.03.094

[40] Furukawa Y., Ueda F., Hyodo Y., Harada I., Nakajima T., Kawagoe T.: Vibrational spectra and structure of polyaniline. Macromolecules, 21, 1297-1305 (1988). https://doi.org/10.1021/ma00183a020

[41] Cui L., Chao D., Zhang J., Mao H., Li Y., Wang C.: Synthesis and properties of novel electroactive polyamide containing crown ether in the main chain. Synthetic Metals, 160, 400-404 (2010).

https://doi.org/10.1016/j.synthmet.2009.11.016

[42] Yeh L-C., Huang T-C., Lin Y-J., Lai G-H., Yang T-I., Lo A-Y., Yeh J-M.: Electroactive polyamide modified carbon paste electrode for the determination of ascorbic acid. International Journal of Green Energy, 13, 13341341 (2016).

https://doi.org/10.1080/15435075.2016.1206005

[43] Chao D., Ma X., Lu X., Cui L., Mao H., Zhang W., Wei Y.: Design, synthesis and characterization of novel electroactive polyamide with amine-capped aniline pentamer in the main chain via oxidative coupling polymerization. Journal of Applied Polymer Science, 104, 16031608 (2007). https://doi.org/10.1002/app.25749

[44] Bindhu M. R., Umadevi M.: Silver and gold nanoparticles for sensor and antibacterial applications. Spectrochimica Acta Part A: Molecular and Biomolecular Spectroscopy, 128, 37-45 (2014). https://doi.org/10.1016/j.saa.2014.02.119

[45] Yeh J-M., Huang K-Y., Lin S-Y., Wu Y-Y., Huang C-C., Liou S-J.: Noncovalent interaction between gold nanoparticles and multiwalled carbon nanotubes via an intermediatory. Journal of Nanotechnology, 2009, 217469/1217469/7 (2009). https://doi.org/10.1155/2009/217469

[46] Zhang M., Lu X., Wang H-Y., Liu X., Qin Y., Zhang P., Guo Z-X.: Porous gold nanoparticle/graphene oxide composite as efficient catalysts for reduction of 4-nitrophenol. RSC Advances, 6, 35945-35951 (2016). https://doi.org/10.1039/C6RA01772J

[47] Wang C., Du J., Wang H., Zou C., Jiang F., Yang P., Du Y.: A facile electrochemical sensor based on reduced graphene oxide and Au nanoplates modified glassy carbon electrode for simultaneous detection of ascorbic acid, dopamine and uric acid. Sensors and Actuators B: Chemical, 204, 302-309 (2014). https://doi.org/10.1016/j.snb.2014.07.077 
[48] Yao H., Jin L., Sue H-J., Sumi Y., Nishimura R.: Facile decoration of Au nanoparticles on reduced graphene oxide surfaces via a one-step chemical functionalization approach. Journal of Materials Chemistry A, 1, 10783 10789 (2013).

https://doi.org/10.1039/C3TA11901G

[49] Chao D., Wang S., Tuten B. T., Cole J. P., Berda E. B.: Densely functionalized pendant oligoaniline bearing poly(oxanorbornenes): Synthesis and electronic properties. Macromolecules, 48, 5054-5057 (2015).

https://doi.org/10.1021/acs.macromol.5b01446

[50] Shahnazari-Shahrezaie E., Nezamzadeh-Ejhieh A.: A zeolite modified carbon paste electrode based on copper exchanged clinoptilolite nanoparticles for voltammetric determination of metronidazole. RSC Advances, 7, 14247-14253 (2017).

https://doi.org/10.1039/C6RA28603H

[51] Nosuhi M., Nezamzadeh-Ejhieh A.: High catalytic activity of $\mathrm{Fe}(\mathrm{II})$-clinoptilolite nanoparticales for indirect voltammetric determination of dichromate: Experimental design by response surface methodology (RSM). Electrochimica Acta, 223, 47-62 (2017).

https://doi.org/10.1016/j.electacta.2016.12.011

[52] Liu C., Hayashi K., Toko K.: Au nanoparticles decorated polyaniline nanofiber sensor for detecting volatile sulfur compounds in expired breath. Sensors and Actuators B: Chemical, 161, 504-509 (2012).

https://doi.org/10.1016/j.snb.2011.10.068

[53] Abdulla S., Dhakshanamoorthi J., Dinesh V. P., Pullithadathil B.: Controlled fabrication of highly monodispersed, gold nanoparticles grafted polyaniline (Au@PANI) nanospheres and their efficient ammonia gas sensing properties. Journal of Biosensors and Bioelectronics, 6, 1000165/1-1000165/5 (2015).

https://doi.org/10.4172/2155-6210.1000165
[54] Feng X., Zhang Y., Yan Z., Ma Y., Shen Q., Liu X., Fan Q., Wang L., Huang W.: Synthesis of polyaniline/Au composite nanotubes and their high performance in the detection of NADH. Journal of Solid State Electrochemistry, 18, 1717-1723 (2014).

https://doi.org/10.1007/s10008-014-2407-1

[55] Raoof J-B., Ojani R., Kiani A.: Carbon paste electrode spiked with ferrocene carboxylic acid and its application to the electrocatalytic determination of ascorbic acid. Journal of Electroanalytical Chemistry, 515, 4551 (2001). https://doi.org/10.1016/S0022-0728(01)00642-8

[56] Zuo X., Li N., Zhang H.: Direct electrochemical determination of ascorbic acid by a cobalt(II) tetra-neopentyloxy phthalocyanine-multi-walled carbon nanotubes glassy carbon electrode. Journal of Materials Science, 47, 2731-2735 (2012). https://doi.org/10.1007/s10853-011-6099-y

[57] Ambrosi A., Morrin A., Smyth M. R., Killard A. J.: The application of conducting polymer nanoparticle electrodes to the sensing of ascorbic acid. Analytica Chimica Acta, 609, 37-43 (2008).

https://doi.org/10.1016/j.aca.2007.12.017

[58] Hou T., Gai P., Song M., Zhang S., Li F.: Synthesis of a three-layered $\mathrm{SiO}_{2} @ \mathrm{Au}$ nanoparticle@polyaniline nanocomposite and its application in simultaneous electrochemical detection of uric acid and ascorbic acid. Journal of Materials Chemistry B, 4, 2314-2321 (2016). https://doi.org/10.1039/C5TB02765A

[59] Qi S., Zhao B., Tang H., Jiang X.: Determination of ascorbic acid, dopamine, and uric acid by a novel electrochemical sensor based on pristine graphene. Electrochimica Acta, 161, 395-402 (2015).

https://doi.org/10.1016/j.electacta.2015.02.116

[60] Han D., Han T., Shan C., Ivaska A., Niu L.: Simultaneous determination of ascorbic acid, dopamine and uric acid with chitosan-graphene modified electrode. Electroanalysis, 22, 2001/1-2001/8 (2010).

https://doi.org/10.1002/elan.201000094 